\title{
Cervical cancer in Tosamaganga Hospital, Tanzania: difficulties and challenges in a low resource country setting
}

\author{
Edoardo Cola, Roma, Italy; Donald Maziku, Tosamaganga, United Republic of Tanzania; Giovanni F Torelli,
} Tosamaganga, United Republic of Tanzania and Anna Fagotti, Rome, Italy

Cervical cancer is the second most common cancer among women, and nearly $90 \%$ of deaths fr cervical cancer occur among women living in low and middle income countries. ${ }^{12}$ The primary cause of such high disease prevalence is the increasing incidence of high-risk human papillomavirus and HIV infection. In Eastern Africa, WatsonJones et al reported a $74 \%$ frequency of human papillomavirus among 142 sexually active healthy young African females in Tanzania. $^{3}$

Our setting is the Tosamaganga District Designated Hospital (figure 1) situated in the District of Iringa DC, region of Iringa, Tanzania. It is a rural area $500 \mathrm{~km}$ southwest of Dar es Salaam, which has undergone fast socio-economical changes in the last years. Nevertheless, health indicators are still alarming. The incidence of HIV is approximately $13 \%$.

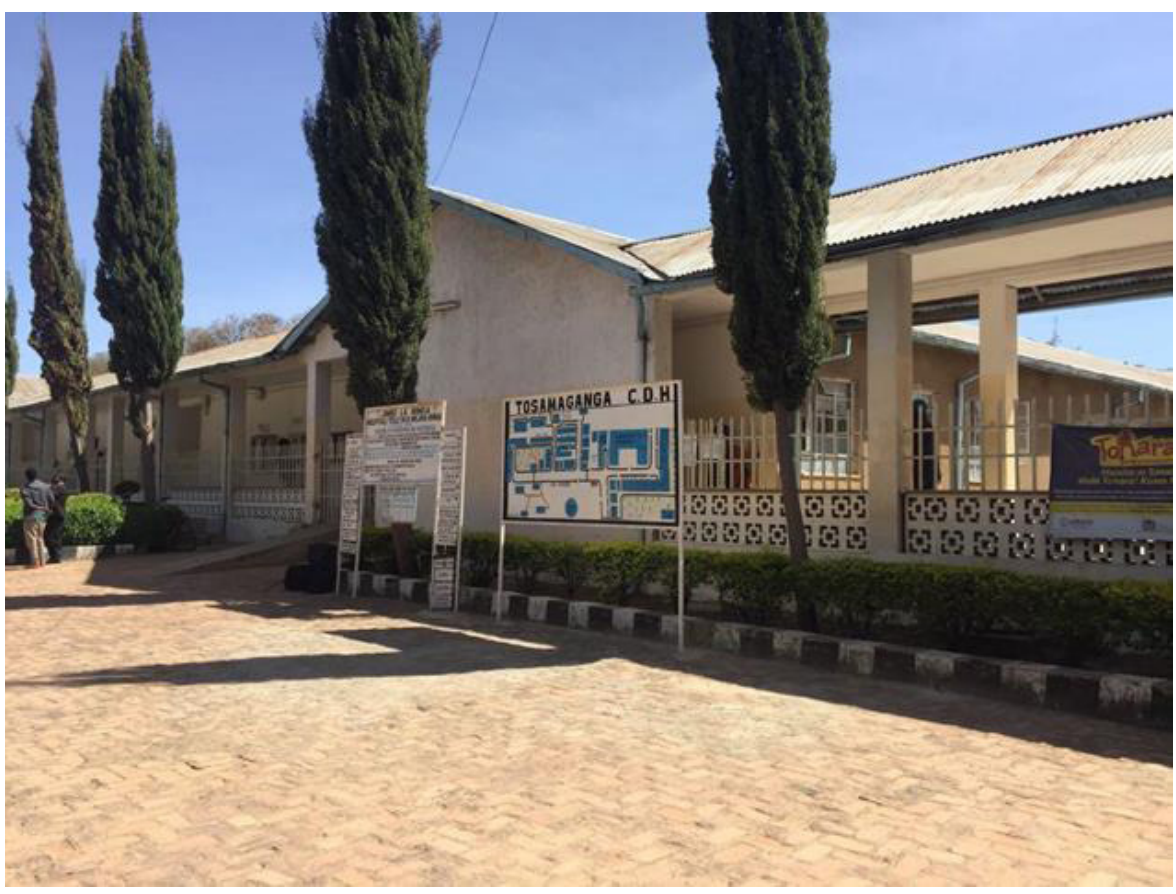

Figure 1 The main entrance of Tosamaganga Hospital.
We see an average of 80 patients with cervical cancer per year in our small hospital. Secondary prevention (Pap smear, colposcopy) is not routinely undertaken for women, even though we offer free screening in our hospital. The primary reason for this is the lack of awareness across the region. As a result, patients are often diagnosed with locally advanced cervical cancer at the time of initial presentation, and access to appropriate treatment is very limited. Currently, chemotherapy and radiotherapy are available only in the cities of Dodoma and Dar es Salaam. Traveling to Dar es Salaam takes approximately 10 hours by bus from Tosamaganga, and the cost required for women is prohibitive. The government has started a program for primary prevention of cervical cancer in secondary school, vaccinating girls up to 16 years of age for human papillomavirus since 2017, and results are expected for 2025.
Doctors with Africa CUAMM (Collegio Universitario Aspiranti Medici Missionari, University College for Missionary Doctors) have supported Tosamaganga District Designated Hospital for more than 30 years. It is a non-government organization founded in 1950, working for the promotion and protection of health in Africa. The chances of receiving surgical treatment for cervical cancer in Tosamaganga are limited by several factors. The majority of patients come to the hospital with locally advanced disease, and surgery is not the indicated treatment. Even in the setting when radical treatment is appropriate, it is not performed because of inadequate anesthesia and surgery (figure 2). Typically, if a patient requires anesthesia for more than 2 hours 30 min then it is not considered safe. Given the fact that radical hysterectomies are not performed secondary to lack of expertise in performing such procedures, as an alternative, nurses and other related healthcare personnel perform only cryosurgery in patients with early-stage cervical cancer.

In conclusion, primary and secondary prevention must be implemented by an effective information campaign aimed at reducing cervical cancer in Africa. However, those women affected by early-stage and locally advanced cervical cancer should have access to safe surgery and/or radiotherapy. An exchange of skills with specialized surgeons and anesthesiologists would help us to provide an opportunity to treat these patients.

Currently CUAMM is implementing a program of primary prevention by supporting an educational campaign on the issue, and secondary prevention by introducing colposcopy and free screening. The next step would be to develop exchange programs for the local staff of rural hospitals 


\section{Corners of the World}

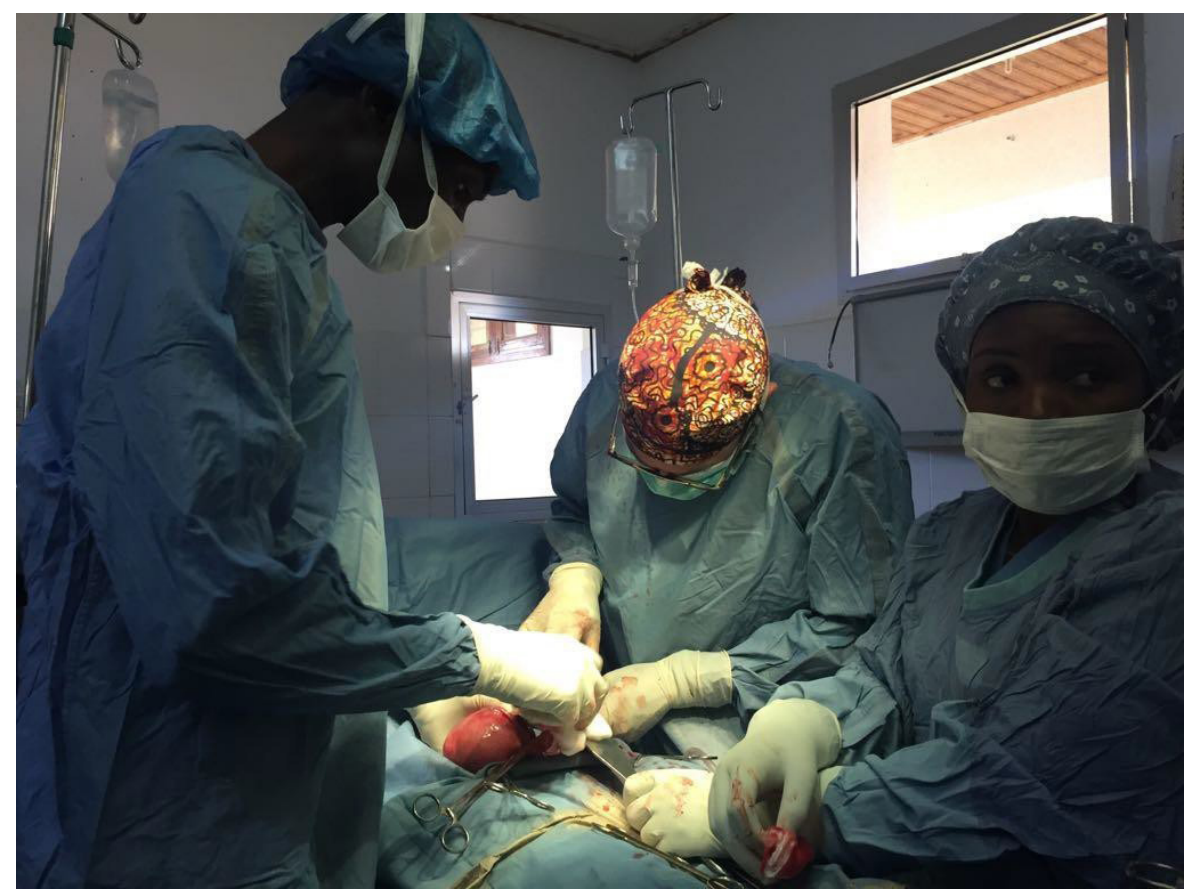

Figure 2 Dr Cola and Dr Maziku performing a simple hysterectomy in the main operating theater at Tosamaganga Hospital.

in order to guarantee safe and appropriate surgery.

Correspondence to Dr Edoardo Cola, Department of Obstretics and Gynecology, Universita Cattolica del Sacro Cuore, Rome 00168, Italy; dodocola89@gmail. com
Funding The authors have not declared a specific grant for this research from any funding agency in the public, commercial or not-for-profit sectors.

Competing interests None declared.

Patient consent for publication Not required.

Provenance and peer review Commissioned; internally peer reviewed.

(c) IGCS and ESGO 2019. No commercial re-use. See rights and permissions. Published by BMJ.

D) Check for updates

To cite Cola E, Maziku D, Torelli GF, et al. Int J Gynecol Cancer 2019;29:1336-1337.

Accepted 15 April 2019

Published Online First 19 July 2019

Int J Gynecol Cancer 2019;29:1336-1337.

doi:10.1136/ijgc-2019-000505

\section{REFERENCES}

1. Einstein $\mathrm{MH}, \mathrm{Ndlovu} \mathrm{N}$, Lee $\mathrm{J}$, et al. Cisplatin and radiation therapy in HIVpositive women with locally advanced cervical cancer in sub-Saharan Africa: a phase II study of the AIDS Malignancy Consortium. Gynecol Oncol 2019;153:20-5.

2. Ndlovu N, Kambarami R, N. Ndlovu, R. K. Factors associated with tumour stage at presentation in invasive cervical cancer. Cent Afr J Med 2003;49:107-11.

3. Watson-Jones D, Baisley K, Brown J, et al High prevalence and incidence of human papillomavirus in a cohort of healthy young African female subjects. Sex Transm Infect 2013;89:358-65. 